\title{
Stress Evaluation at the Maximum Strained State by EBSD and Several Residual Stress Measurements for Plastic Deformed Austenitic Stainless Steel
}

\author{
Yohei Sakakibara, Keiji Kubushiro \\ IHI Corporation, Research Laboratory: 1, Shin-Nakahara cho, Isogo ku, Yokohama shi, Japan \\ Email: yohei_sakakibara@ihi.co.jp
}

How to cite this paper: Sakakibara, Y. and Kubushiro, K. (2017) Stress Evaluation at the Maximum Strained State by EBSD and Several Residual Stress Measurements for Plastic Deformed Austenitic Stainless Steel. World Journal of Mechanics, 7, 195-210. https://doi.org/10.4236/wjm.2017.78018

Received: July 3, 2017

Accepted: August 15, 2017

Published: August 18, 2017

Copyright ( 92017 by authors and Scientific Research Publishing Inc. This work is licensed under the Creative Commons Attribution International License (CC BY 4.0).

http://creativecommons.org/licenses/by/4.0/ (c) (i) Open Access

\begin{abstract}
This paper studies a method for obtaining the stress with plastic deformation by finding the plastic strain on U-bent specimens of austenitic stainless steel that have been subjected to large plastic deformation using the EBSD (Electron Backscatter Diffraction) method. The Mises stress calculated on the basis of the KAM of the EBSD shows good agreement with the stress that can be geometrically calculated from the U-bent specimens. In contrast, general methods for measuring residual stress on the basis of elastic strain produce residual stress measurement results that differ specimen by specimen. Thus, for true strain not less than 0.05 , stress estimation based on the EBSD method produces better results than other general methods.
\end{abstract}

\section{Keywords}

Stainless Steel, EBSD, Plastic Strain, Misorientation

\section{Introduction}

The methods that have been used for evaluating residual stress on structures include the X-ray diffraction method [1], the Sectioning method [2], and the center hole drilling methods (CHD) and deep hole drilling (DHD) [3]. These methods have also been used for deliberations on manufacturing methods. However, these methods cannot be used for structures that have already exhibited damage as that means the residual stress has already been released because they are adapted to evaluating stress using elastic strain.

Recently, based on the EBSD method, the so-called cross court method was 
established to enable elastic strain and stress to be calculated from deviations from the Kikuchi patterns [4] [5]. This method simply compares the Kikuchi pattern of specific measurement points with other measurements for the same crystal grains in the same samples, and therefore it can only be used for the estimation of elastic strain and stress relative to reference points remaining in the samples. In the first place, the method cannot be used to obtain absolute values of elastic stress because elastic strain is mostly released when samples are taken out of structures.

In contrast, the EBSD method has been studied by many researchers as an analytical method for plastic strain [6] [7] [8] [9] [10]. Considering that plastic strain remains unchanged in areas around damage due to a crack (excluding the immediate vicinity even after residual stress is released), for example, the EBSD method can significantly contribute to understanding actual phenomena in a manner that estimates the stress before the damage on the basis of the evaluation of plastic strain obtained through the EBSD method. Kamaya evaluated the distribution of plastic strain in a stress concentration section on a notched bottom using the EBSD and FEA (Finite Element Analysis) methods and found out that the distribution patterns based on the two methods were almost identical [11], which suggests that the stress dependency in the plate thickness direction can be estimated if the stress can be calculated from the plastic strain obtained through the EBSD method. Here, EBSD method is limited for surface measurement and no $z$-directional stress can be obtained.

The misorientation measured with the EBSD method is based on GND (Geometrically Necessary Dislocation) density [12] [13] [14] [15]. Because GND density is a dislocation density necessary for plastic deformation, the increment in stress due to work hardening has a correlation with the GND density. That is, there is a possibility of estimating the increment in stress due to work hardening from changes in the KAM (Kernel Average Misorientation) obtained through the EBSD method. Figure 1 shows schematic illustration of typical stress-strain curves of materials with high work hardening ratio. Value of elastic strain is very small and the change in plastic strain $\left(\varepsilon_{p 1}\right.$ to $\left.\varepsilon_{p 2}\right)$ is larger relative to elastic strain $\left(\varepsilon_{e 1}\right.$ to $\left.\varepsilon_{e 2}\right)$, when applied stress increases from $\sigma_{1}$ to $\sigma_{2}$. If misorientation caused by work hardening was large enough, stress could be evaluated by using KAM. In the course of our study on the relationship between the KAM and plastic strain, we attempted to apply a more simplified approach in this paper that estimates the stress with the plastic strain obtained through the EBSD method and a true stress-strain curve. Here, because stress and strain each have their own directional components, it is necessary to consider the misorientation obtained through the EBSD method. Ramazani et al. estimated the distribution of Mises stress with a method using a computer model called "Representative Volume Element" and found that the distribution showed good agreement with that of the KAM obtained through the EBSD method [16]. This suggests that the KAM obtained through the EBSD method has a correlation with Mises stress which is 


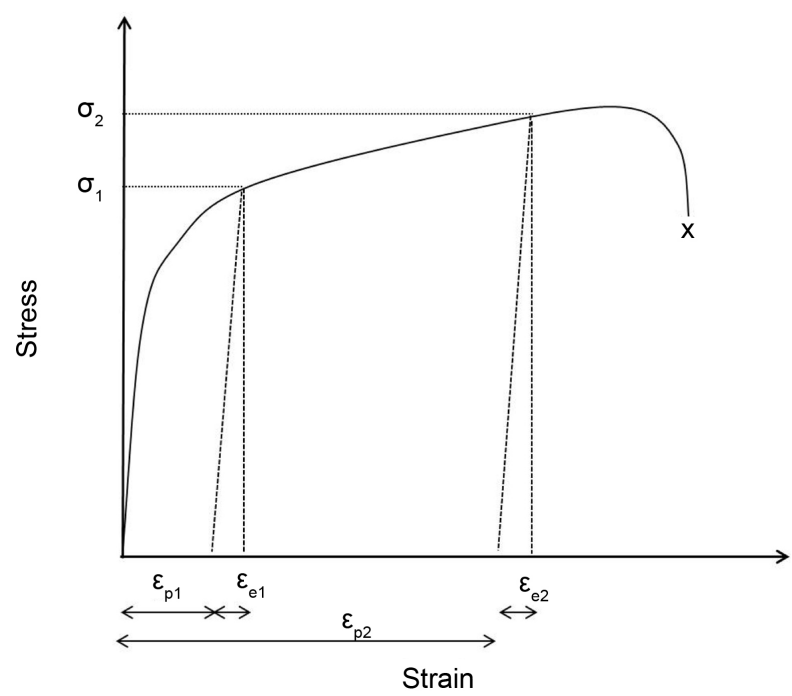

Figure 1. Schematic illustration of stress-strain curve of materials with high work hardening ratio.

the true stress obtainable in uniaxial tensile tests. Thus, even for unknown samples with a complicated deformation history, the relationship between the KAM and the true strain preliminarily obtained from the samples taken out of the specimens for which tensile tests are interrupted enables the Mises stress of the uniaxial tests to be estimated in a manner that evaluates the true strain by measuring the KAM of the unknown samples through the EBSD method.

Therefore, in this paper, the stress on the U-bent specimens (prepared as samples subjected to large plastic deformation) obtained through several conventional residual stress measuring methods is compared with the Mises stress estimated by the evaluation of the plastic strain through the EBSD method and the characteristics of these methods are discussed to show the validity of the new proposal.

\section{Experimental Procedure}

Tensile test specimens and U-bent specimens were taken out of large diameter type $316 \mathrm{NG}$ piping that had the chemical composition shown in Table 1. Figure 2 shows the shapes of the tensile test specimens and the U-bent specimens. Table 2 summarizes the test for each U-bent sample. These specimens were prepared so that the longitudinal direction of the specimens coincides with the axial direction of the piping. The tensile tests were conducted at room temperature and were interrupted when the true strain ranges from 0.049 to 0.262 . The specimens were then cut in the longitudinal direction, mirror finished by diamond and colloidal silica polishing and subjected to the EBSD measurement. In the EBSD measurement, data acquisition and analyses were performed with OIM system ver. 6 by TSL Solution Co., Ltd. to investigate the relationship between true strain and the KAM. Table 3 shows the measurement conditions. The observations were conducted for 3 areas under each condition and the 
Table 1. Chemical composition of materials.

\begin{tabular}{cccccccccc}
\hline $\mathrm{C}$ & $\mathrm{Si}$ & $\mathrm{Mn}$ & $\mathrm{P}$ & $\mathrm{S}$ & $\mathrm{Ni}$ & $\mathrm{Cr}$ & $\mathrm{Fe}$ & $\mathrm{Mo}$ & $\mathrm{N}$ \\
\hline 0.019 & 0.42 & 1.41 & 0.024 & 0.005 & 12.62 & 17.06 & Bal. & 2.6 & 0.105 \\
\hline
\end{tabular}

Table 2. Test methods for each U-bent sample.

\begin{tabular}{cc}
\hline Method & Specimen \\
\hline XRD, EBSD & Specimen \#1 \#3 \\
Strain gage & Specimen \#4 \#6 \\
Center hole drilling & Specimen \#7 \#9 \\
\hline
\end{tabular}

Table 3. Measurement conditions of EBSD observation.

\begin{tabular}{cc}
\hline Software & TSL OIM ver.6 \\
\hline Voltage & $20 \mathrm{kV}$ \\
Working Distance & $15 \mathrm{~mm}$ \\
Pitch & $2 \mathrm{~mm}$ \\
Area & $400 \times 1000 \mathrm{~mm}$ \\
Binning & $4 \times 4$ \\
q step size & 0.5 degree \\
Number of measure & 3 times per a specimen \\
\hline
\end{tabular}

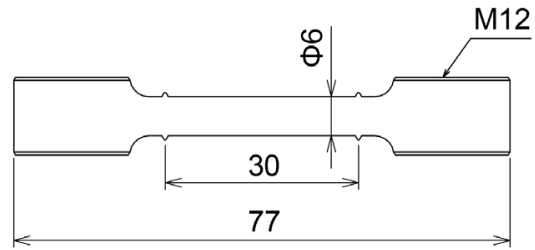

(a)
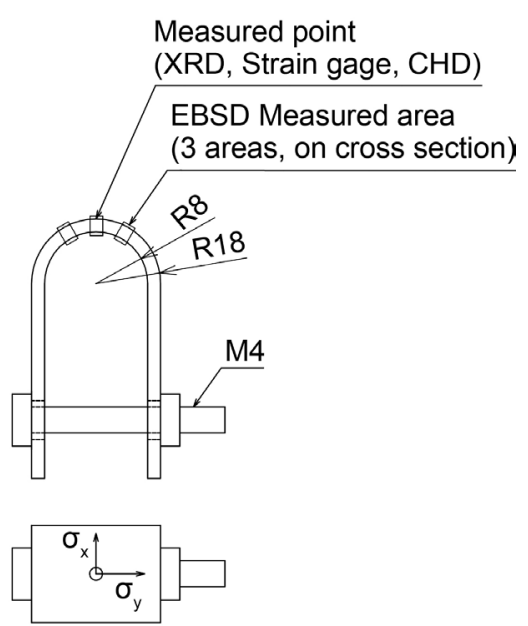

(b)

Figure 2. Schematic illustration of test specimens (a) tensile test specimen, (b) $U$ bent specimen.

relationship was evaluated with the average $\mathrm{KAM}$ value $\left(\mathrm{KAM}_{\text {Ave, Area }}\right)$ in those areas. An adjacent number can be selected in calculating the KAM. In this paper, misorientation of a specific measurement point with respect to 6 neighboring points was calculated using the adjacent number of 1 . That is, the KAM value at a given measurement point can be calculated by the following equation:

$$
\mathrm{KAM}=\sum_{n=1}^{6} \theta_{n} / 6
$$


where $\theta_{n}$ is misorientation between an ambient point and its surrounding points. Three U-bent specimens for each measurement method were prepared by bending specimens $2 \mathrm{~mm}$ in thickness with a bending jig having an $8 \mathrm{~mm}$ radius and the residual stress on the U-bent specimens was measured through each measurement method. The specimens were bent in a manner that keeps the distance between legs in the range of $16+0.1 /-0.3 \mathrm{~mm}$. U-bent specimen with 2 $\mathrm{mm}$ thickness was used because it was easy to control to the distance. Then, the residual stress was measured with the bolts on the specimens fastened to control the distance between legs. If the bolts are loosened from a state where the distance between the legs is not more than $16 \mathrm{~mm}$, the residual stress is reduced with respect to the applied plastic strain. Thus, the measurement of the residual stress was implemented with special care so as to not loosen the bolts.

The methods used for measuring the residual stress were the X-ray diffraction method, strain gauge method and center hole drilling method. In each method, a Young's modulus of $196 \mathrm{GPa}$ was used to calculate the stress. The measurement conditions are summarized in Tables 4-6. The X-ray diffraction method called the side inclination method was used for measuring stress. In this method, specimens were scanned in the direction parallel to a bending direction. The outer

Table 4. Measurement conditions of X-ray side inclination method.

\begin{tabular}{cc}
\hline Apparatus & Stress tech X3000 \\
\hline X-ray tube & $\mathrm{Mn}-\mathrm{Ka}$ \\
X-ray tube voltage & $30 \mathrm{kV}$ \\
X-ray tube current & $6.7 \mathrm{~mA}$ \\
Lattice plane & $\{311\}$ \\
Diffraction peak & $152.26 \mathrm{degree}$ \\
Area & $\mathrm{f} 1.0 \mathrm{~mm}$ \\
Young's modulus & $196 \mathrm{GPa}$ \\
Poisson's ratio & 0.28 \\
Depth & $20 \mathrm{~mm}$ \\
& $500 \mathrm{~mm}$ \\
\hline
\end{tabular}

Table 5. Measurement conditions of sectioning method.

\begin{tabular}{cc}
\hline \multirow{2}{*}{ Apparatus } & Tokyo Measuring Instruments Laboratory \\
\cline { 2 - 2 } Strain gage & TDS-303 \\
Strain gage size & KFG-1-120-D16-16 \\
Strain gage type & $1 \mathrm{~mm}$ \\
Young's modulus & biaxial \\
Machined size & $196 \mathrm{GPa}$ \\
& $15 \times 15 \mathrm{~mm}$ \\
\end{tabular}


Table 6. Measurement conditions of center hole drilling method.

\begin{tabular}{cc}
\hline Apparatus & SINT MTS3000 \\
Rosette gage & Tokyo Measuring Instruments Laboratory \\
Rosette gage type & FRS-2-17 \\
Rosette gage diameter & Type A (ASTM) \\
Hole diameter & $5.10 \mathrm{~mm}$ \\
Decentering & $1.770 \mathrm{~mm}$ \\
Pitch (depth) & $0.005 \mathrm{~mm} \mathrm{Max}$. \\
Young's modulus & $50 \mathrm{~mm}$ \\
Poisson's ratio & $196 \mathrm{GPa}$ \\
& 0.28 \\
\hline
\end{tabular}

surfaces of U-bent specimens were mirror finished by electrolytic polishing with a depth of concave of approximately $20 \mu \mathrm{m}$. The first measurement of the residual stress was conducted under these conditions. Then, the second measurement was conducted after finishing the surfaces of the same specimens by electrolytic polishing with a concave depth of $500 \mu \mathrm{m}$. In the strain gauge method, the stress was evaluated after cutting specimens into test pieces of $15 \times 15 \mathrm{~mm}$ and then $10 \times 10 \mathrm{~mm}$ to investigate the effect of cut size on measurement results. In the center hole drilling method, released strain was measured at $50 \mu \mathrm{m}$ intervals and the profiles of the residual stress in the depth direction were established.

Last, in the EBSD method, the EBSD on the cross sectional surfaces at the center in the longitudinal direction of the U-bent specimens was measured in a manner that scanned each cross sectional surface along three lines in the plate thickness direction with each line made up of a series of segments having 200 $\mu \mathrm{m}$ in the plate thickness direction and $400 \mu \mathrm{m}$ in the bending direction. Then, the plastic strain in the U-bent specimens was analyzed and the analysis results were used to estimate the stress applied by bending along with the tensile test results.

\section{Results and Discussion}

\subsection{EBSD Observation of Interrupted Tensile Test Specimens}

Figure 2 shows the true stress-true strain curve and work hardening ratios when the tensile test was interrupted with a strain $\varepsilon$ of 0.26 . It can be seen that the work hardening ratio is very high in the range of the strain $\varepsilon$ up to 0.02 , stable in the range of strain $\varepsilon$ from 0.02 to 0.15 , and gradually decreases as the strain $\varepsilon$ increases from 0.15. Figure 3 shows the IPF (Inter Pole Figure) map obtained through the EBSD observations of the specimens with the tensile test interrupted at each strain value. The graduations inside the grains gradually intensify as the applied strain gets larger. Figure 4 shows the enlarged IQ map of the grain boundary characters with a true strain of not less than 0.18 . As indicated in blue lines, thin plate-like regions with identical orientations can be found in the grains. Because the crystal grain orientations inside and outside the plates satisfy 


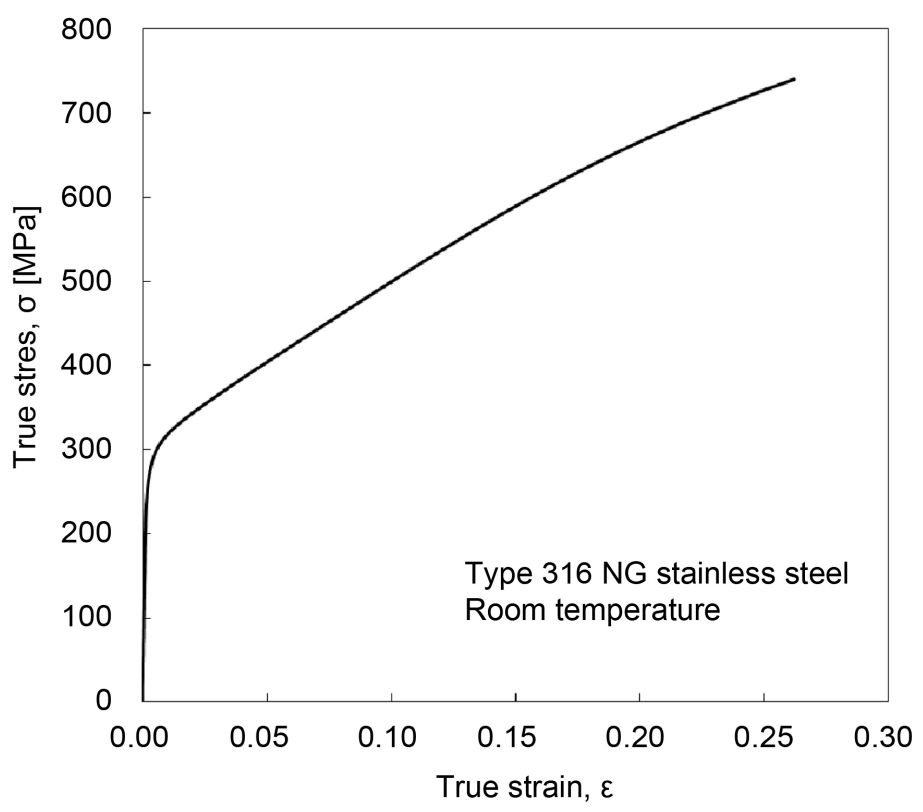

(a)

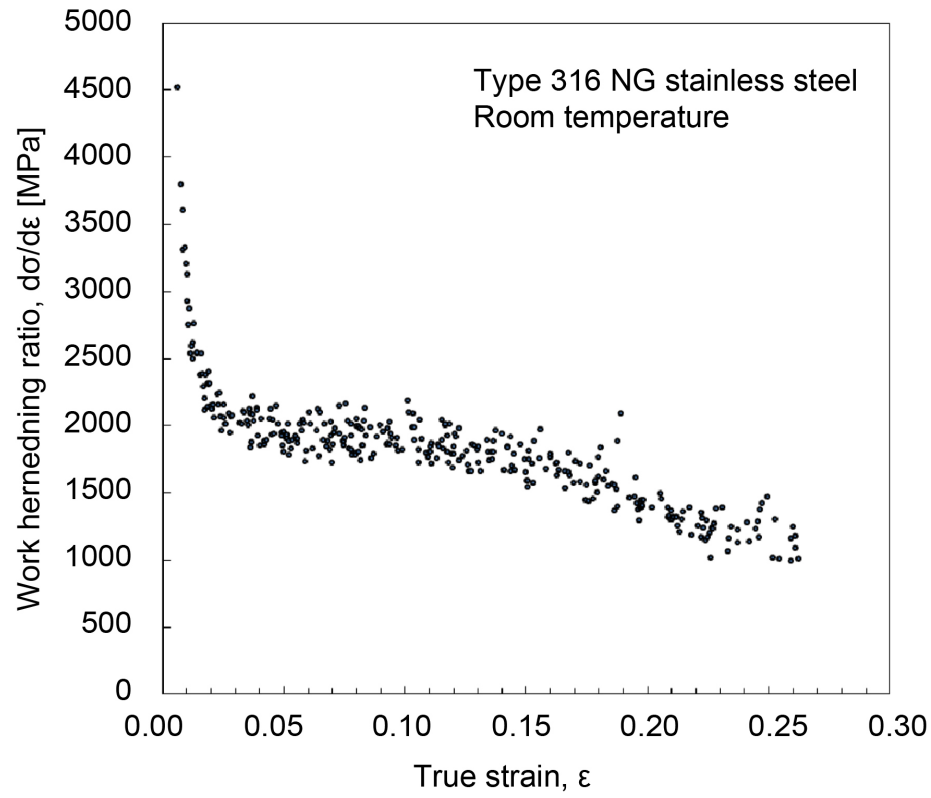

(b)

Figure 3. Stress-strain curve (a) and work hardening ratio (b).

the $\Sigma 3$ relation as shown in Figure 4, the crystal grains are considered to be deformation twins. Figure 5 shows the relationship between the calculated KAM values and true strain. They show a good linear relationship until the strain $\mathcal{E}$ reaches 0.18 but the increments of the KAM values decrease as the strain $\varepsilon$ gets larger. As described above, this is attributable to the relaxation of the strain by the deformation twins in the region where the strain $\varepsilon$ is not less than 0.18 . It is also thought that the generation of strain-induced martensite prevented misorientation from being produced, thereby decreasing the increment of the KAM values. 

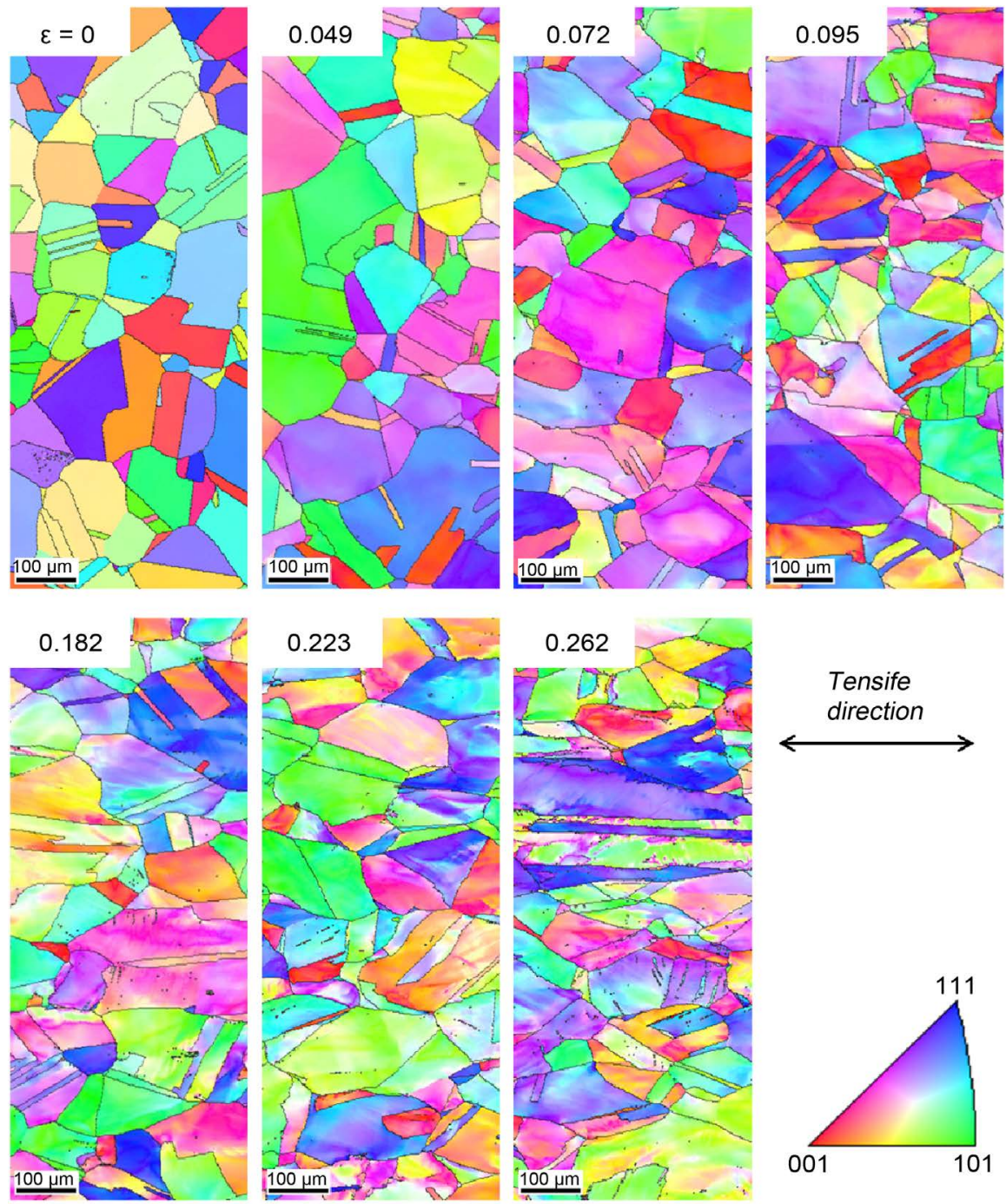

Figure 4. Inter pole figure maps of tensile specimens interrupted at various strain.

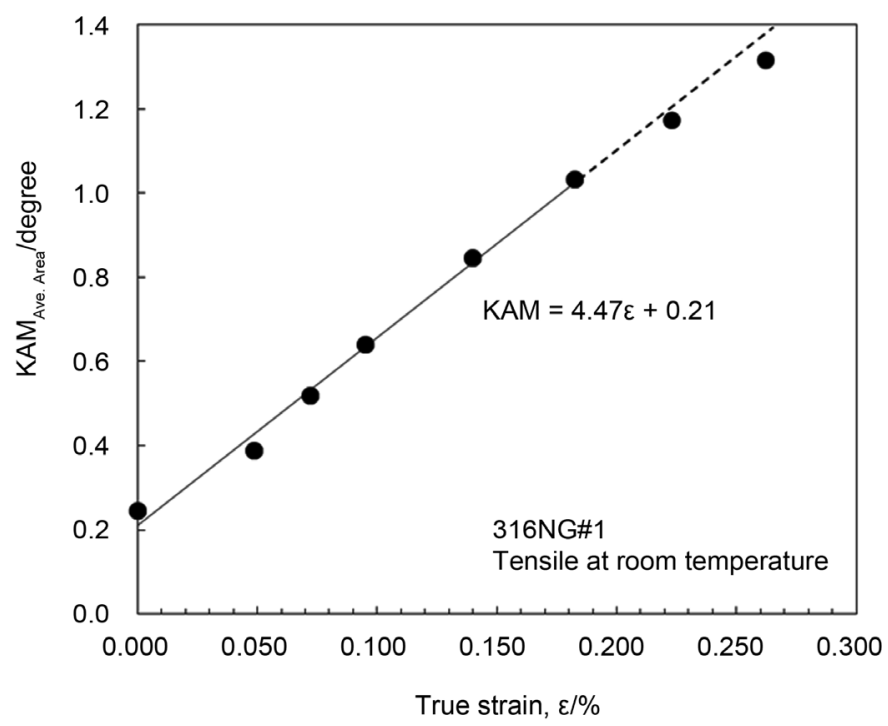

Figure 5. Relationship between kernel average misorientation and true strain. 


\subsection{Comparison of Residual Stress Measurement Results for U-Bent Specimens by Several Methods}

Given that the thickness center of the U-bent specimen is the center line of bending, the true strain $\mathcal{E}$ due to bending on specimens in a plane strain state is given by the following equation:

$$
\varepsilon=\ln \left(\frac{l}{l_{0}}\right)=\ln \left(\frac{R+1+\delta t}{R+1}\right)
$$

where $l$ and $l_{0}$ are the arc length after and before bending, $\delta t$ is the thickness from the thickness center line and $R$ is the inner bending radius with a value of 8 $\mathrm{mm}$ in this case. Because the plate thickness is $2 \mathrm{~mm}$, the bending radius at the center line becomes $9 \mathrm{~mm}$. Based on Equation (2) and the relationship between true stress and true strain in Figure 2, the distribution of residual stress in the plate thickness direction is estimated as shown in Figure 6. According to the distribution, the residual stress on the outer surface and at the point $500 \mu \mathrm{m}$ from the outer surface can be estimated at $509 \mathrm{MPa}$ and $412 \mathrm{MPa}$ respectively.

In the following section, the calculation results in Figure 6 are compared with the results of several residual stress measurement methods. The residual stress measurement results of the X-ray diffraction, strain gauge, and center hole drilling methods are shown in Table 7. In the X-ray diffraction method, the residual stress on the surface $(20 \mu \mathrm{m})$ is higher than one at $500 \mu \mathrm{m}$ of depth. This result agrees with the tendency in Figure 6. Also, in the X-ray diffraction method, the average residual stress at the points $20 \mu \mathrm{m}$ and $500 \mu \mathrm{m}$ from the outer surface is $549 \mathrm{MPa}$ and $484 \mathrm{MPa}$ respectively, which are higher than the values estimated with Equation (1) and Figure 2 by $40 \mathrm{MPa}$ and $60 \mathrm{MPa}$ respectively. In addition, three specimens had large variations in the residual stress, $176 \mathrm{MPa}$ at the point

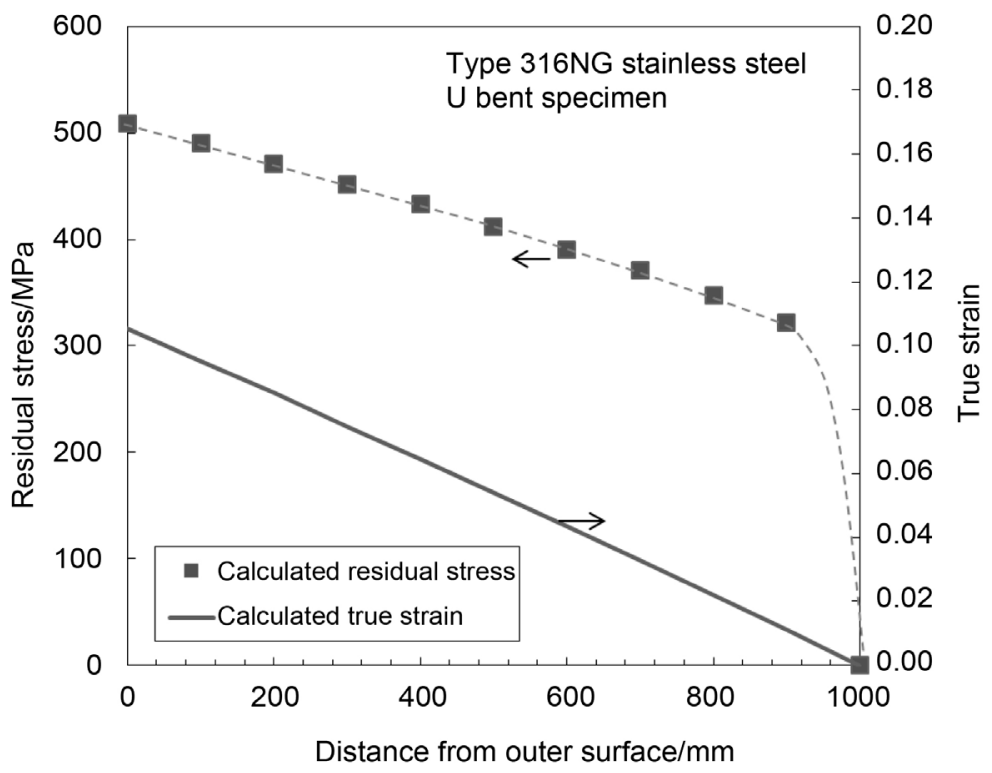

Figure 6. Distribution of plasticstrain calculated geometrically and residual stress in the plate thickness direction. 
Table 7. Comparison of residual stress by X-ray, Sectioning method and center hole drilling method.

\begin{tabular}{|c|c|c|c|c|c|c|c|}
\hline Method & Specimen & \multicolumn{3}{|c|}{ at $20 \mathrm{~mm}$} & \multicolumn{3}{|c|}{ at $500 \mathrm{~mm}$} \\
\hline & Specimen \#1 & \multicolumn{3}{|c|}{439} & \multicolumn{3}{|c|}{409} \\
\hline & Specimen \#2 & \multicolumn{3}{|c|}{595} & \multicolumn{3}{|c|}{510} \\
\hline \multirow[t]{5}{*}{ X-ray } & Specimen \#3 & \multicolumn{3}{|c|}{615} & \multicolumn{3}{|c|}{533} \\
\hline & Average & \multicolumn{3}{|c|}{549} & \multicolumn{3}{|c|}{484} \\
\hline & Max-min. & \multicolumn{3}{|c|}{176} & \multicolumn{3}{|c|}{124} \\
\hline & & \multicolumn{3}{|c|}{$10 \times 10 \mathrm{~mm}$} & \multicolumn{3}{|c|}{$15 \times 15 \mathrm{~mm}$} \\
\hline & & $s_{X}$ & $s_{y}$ & Mises & $s_{X}$ & $s_{y}$ & Mises \\
\hline \multirow{6}{*}{ Sectioning } & Specimen \#4 & 105 & 476 & 433 & 143 & 444 & 393 \\
\hline & Specimen \#5 & 111 & 734 & 685 & 132 & 710 & 654 \\
\hline & Specimen \#6 & 116 & 639 & 590 & 148 & 612 & 553 \\
\hline & Average & 111 & 616 & 569 & 141 & 589 & 533 \\
\hline & \multirow[t]{2}{*}{ Max-min. } & 11 & 258 & 252 & 16 & 266 & 262 \\
\hline & & $\sigma_{X}$ & $\sigma_{y}$ & Mises & & & \\
\hline \multirow{5}{*}{$\begin{array}{l}\text { Center hole } \\
\text { drilling } \\
\text { methods } \\
\text { (at } 500 \mathrm{~mm} \text { ) }\end{array}$} & Specimen \#7 & 423 & 790 & 685 & & & \\
\hline & Specimen \#8 & 290 & 575 & 501 & & & \\
\hline & Specimen \#9 & 281 & 513 & 448 & & & \\
\hline & Average & 331 & 626 & 545 & & & \\
\hline & Max-min. & 143 & 277 & 237 & & & \\
\hline
\end{tabular}

$20 \mu \mathrm{m}$ from the outer surface and $124 \mathrm{MPa}$ at $500 \mu \mathrm{m}$.

As for the residual stress measurement results of the strain gauge method, the stress in the bending direction $\sigma_{y}$ is larger than the stress in the plate width direction $\sigma_{x}$. The Mises stress of the $15 \times 15 \mathrm{~mm}$ test piece and $10 \times 10 \mathrm{~mm}$ test piece is $533 \mathrm{MPa}$ and $569 \mathrm{MPa}$ respectively, which means that the residual stress varies depending on the specimen sizes. Every test piece shows increases in the released elastic strain and the residual stress as the sizes get smaller. The variations in the residual stress of test pieces of respective sizes are: $262 \mathrm{MPa}$ for $15 \times$ $15 \mathrm{~mm}$ test pieces and $252 \mathrm{MPa}$ for $10 \times 10 \mathrm{~mm}$ test pieces. These variations are larger than those of the residual stress measurement results of the X-ray diffraction method.

In the center hole drilling method, the profiles of released strain and residual stress in the depth direction are obtained. The released strain gets larger as the drilling depth is increased as shown in Figure 7. According to the results in Figure 6, the residual stress is supposed to be maximized on the outer surface of the U-bent specimen; however, the residual stress in the center hole drilling method has its peak at the depth of 300 to $500 \mu \mathrm{m}$ with smaller residual stress on the outer surface and decreasing residual stress from that depth toward the thickness center. According to Table 7 which shows the measurement result at the depth of $500 \mu \mathrm{m}$, the average of the residual stress at that depth is $539 \mathrm{MPa}$ 


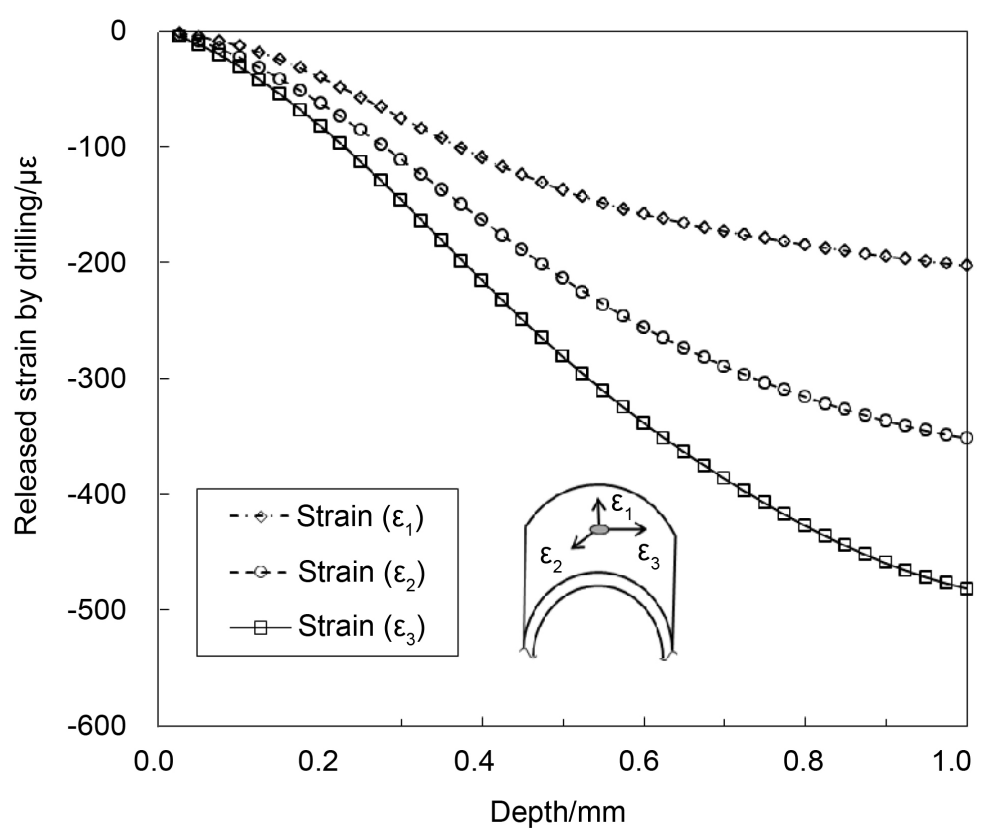

(a)

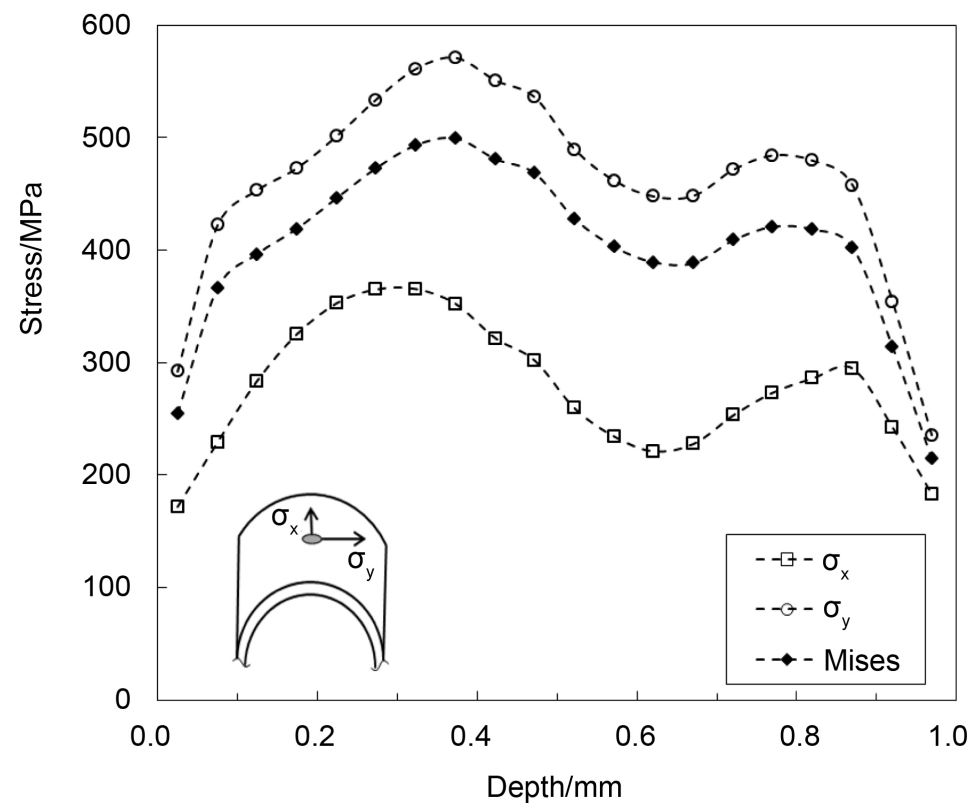

(b)

Figure 7. Residual stress measurement results by center hole drilling method (a) released strain, (b) residual stress profile.

which is higher than the result in Figure 6 and that of the X-ray diffraction method. The variations in the center hole drilling method are similar to those in the strain gauge method.

Regarding the evaluation of the residual stress using the EBSD method, considering that the maximum true strain due to bending of the U-bent specimens, which can be calculated using Equation (2), is 0.11 as explained in 3.2, and that the relationship between bending and true strain shows good linearity until the 
strain $\mathcal{E}$ reaches 0.18 in Figure 4, the linear approximation of the relationship between the KAM and true strain in this strain range can be expressed by the following equation:

$$
\mathrm{KAM}(\text { deg. })=4.47 \varepsilon+0.210
$$

Yoda et al., showed that tensile and compression have the same tendency until the strain $\varepsilon$ reaches 0.10 approximately [8], and it is also assumed in this paper that the Equation (3) can be used for evaluating the strain in the compression half. Figure 8 shows the calculation results of the true strain using Equation (2) after obtaining the average of the KAM values $\left(\mathrm{KAM}_{\text {Ave. Area }}\right)$ in the areas at each depth from the outer surface. The true strain values at all depths are higher than those obtained by Equation (1) but the increments are only about 0.02 . Using the results in Figure 8 and Figure 2, the maximum stress at the maximum strained state due to bending is estimated and the estimation results are shown in Figure 9. In comparison with the results obtained by using Equation (2), the estimated values of the stress at each depth on the basis of the EBSD method have differences of about $30 \mathrm{MPa}$ except the areas close to the inner surface, which means the estimation is quite accurate. Although the theoretical plastic strain at the thickness center is 0 , the EBSD method produces an estimated plastic strain of about 0.02 which can be converted into a significant difference in stress. The large difference in the stress is attributable to Equation (2) which cannot reflect the influences of the friction between the inner surfaces of the U-bent specimens and the bending jig and possible minor deviation of the bending center line from the thickness center line in calculation results. However, considering the variations in the estimated values of the stress on the specimens are $20 \mathrm{MPa}$ at most, the estimation is considered to be precise.

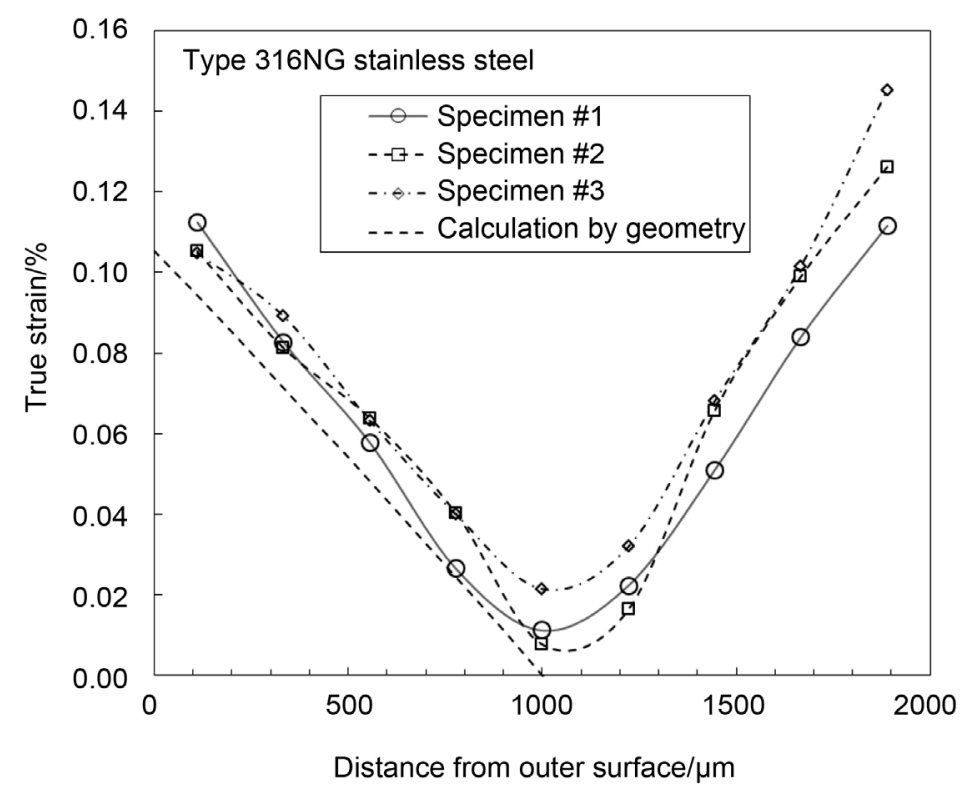

Figure 8. Comparison of geometrically calculated strain with estimated strain by EBSD method. 


\subsection{Discussion}

A comparison of the residual stress estimated by Equation (2) with the measurement results of several methods is shown in Figure 10. Among the studied methods, the EBSD method produced the stress at the maximum strained state closest to that calculated by Equation (2). The strain gauge and center hole drilling methods produced higher measurement results than calculated values with large variations. The average of the stress measurement results in the X-ray diffraction method is close to that in the EBSD method, but the variation in the $\mathrm{X}$-ray diffraction method is larger than that in the EBSD method. This means that even a slight change or an error in measuring the elastic strain can cause a

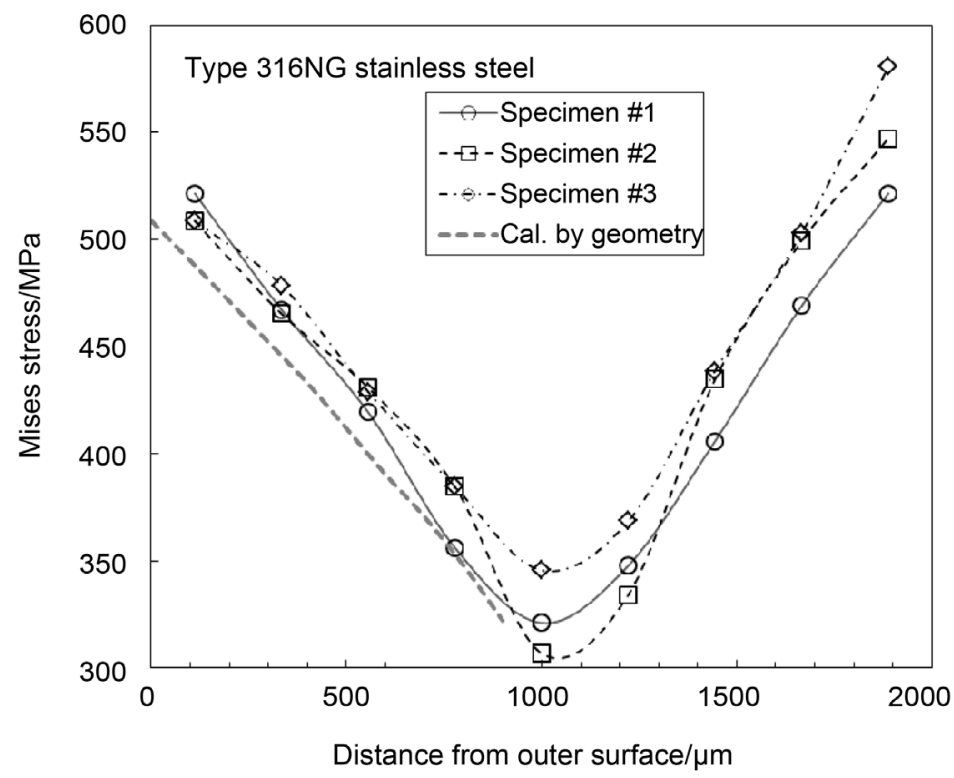

Figure 9. Comparison of geometrically calculated stress with estimated stress by EBSD method.

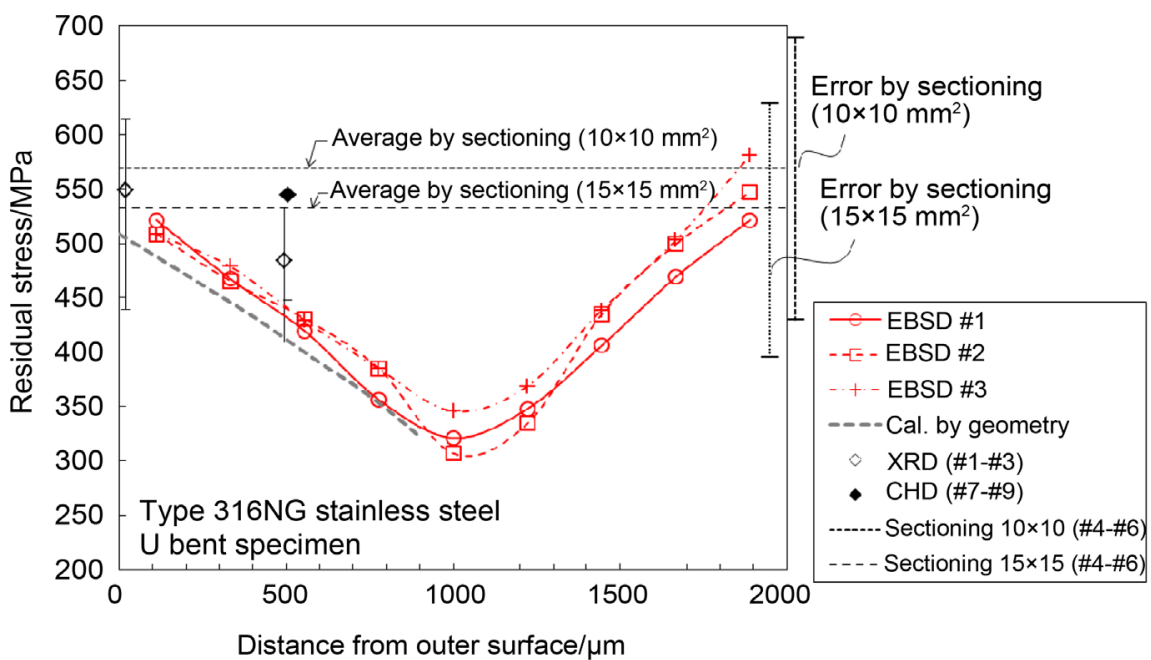

Figure 10. Comparison of geometrically calculated stress with measurement results by $\mathrm{X}$-ray, Sectioning, Center hole drilling method and EBSD. 
very large variation as shown in Figure 1 in the residual stress because the residual stress is calculated by multiplying the elastic strain by the Young's modulus. In contrast, the EBSD method measures GND densities, i.e., plastic strain in calculating the KAM and the stress at the maximum strained state is calculated from the plastic strain using the true stress-true strain curve. Because the work hardening ratio is reduced particularly when the plastic strain is not less than 0.05 , the EBSD method produces very few variations in the stress even though the plastic strain has variations. However, because the work hardening ratio is increased when the true strain is not more than 0.05 and misorientation is hard to be generated when the true strain is not more than 0.02 [17], the residual stress measurement using conventional methods is more suitable than EBSD for obtaining the stress within an elastic limit. The EBSD method is only applicable to the stress with the maximum strained state of specimens and cannot be used for estimating the residual stress with bolts to maintain the bent state loosened as was the case for the U-bent specimens this time. It is necessary to give extra consideration to the ability of the method using elastic strain to obtain the stress on the basis of the state when specimens are measured. EBSD method cannot identify the tensile stress and compressive stress, therefore it is good that the measurement methods with using elastic strain clarify the stress direction at first, and Mises stress is evaluated by EBSD method, and finally FEA justify the stress level and stress direction by using these results. It helps to comprehend stress corrosion cracking and fatigue phenomena.

\section{Conclusions}

In this paper, we compared the measurement results of residual stress on U-bent specimens of type $316 \mathrm{NG}$ stainless steel to which large plastic strain was applied that were found using methods that use elastic strain and the EBSD method measuring plastic strain. The following findings were obtained:

- The KAM values and true strain of type $316 \mathrm{NG}$ stainless steel correspond well with each other until the true strain reaches 0.18 ;

- The plastic strain amounts, with the bent state maintained, calculated from the correlation between the KAM values and the true strain show good agreement with the geometrically calculated plastic strain amounts and the difference in the residual stress amounts respectively converted from the two types of plastic strain amounts using the true stress-true strain curve was negligibly small at $30 \mathrm{MPa}$ except in the thickness centers of the specimens;

- The methods using elastic strain have a tendency to produce higher values of residual stress than the EBSD method using plastic strain, and large variations;

- The EBSD method using plastic strain is suitable for calculating the residual stress when applied strain amounts are not less than 0.05;

- In contrast, the elastic strain method is preferable in the elastic strain range because of the high work hardening ratio and little generation of misorienta- 
tion; and

- EBSD can only predict the Mises stress at the maximum strained state, but cannot predict the stress direction and whether it is tensile or compressive stress.

\section{Acknowledgements}

The authors would like to thank Dr. Mikami and Mr. Sato from IIC for residual stress measurement and tensile test.

\section{References}

[1] Kapoor, K., Lahiri, D., Padmaprabu, C. and Sanyal, T. (2012) X-Ray Measurement of Near Surface Residual Stress in Textured Cold-Worked Stress-Relieved Zr-2.5\%Nb Pressure Tube Material. Journal of Nuclear materials, 303, 147-155.

[2] Tebedge, N., Alpsten, G. and Tall, L. (1973) Residual Stress Measurement by the Sectioning Method. Experimental Mechanics, 13, 88-96. https://doi.org/10.1007/BF02322389

[3] Mathar, J. (1934) Determination of Initial Stresses by Measuring the Deformation around Drilled Holes. Trans. ASME, 56, 249-254.

[4] Wilkinson, A.J., Meaden, G. and Dingley, D.J. (2006) High-Resolution Elastic Strain Measurement from Electron Backscatter Diffraction Patterns: New Levels of Sensitivity. Ultramicroscopy, 106, 307-313.

[5] Karamched, P.S. and Wilkinson, A.J. (2011) High Resolution Electron Back-Scatter Diffraction Analysis of Thermally and Mechanically Induced Strains near Carbide Inclusions in a Superalloy. ActaMaterialia, 59, 263-272.

[6] Fukuoka, C., Morishima, K., Yoshizawa, H. and Mino, K. (2002) Misorientation Development in Grains of Tensile Strained and Crept 2.25\%CR-1\%Mo Steel. Scripta Materialia, 46, 61-66.

[7] Kamaya, M., Wilkinson, A.J. and Titchmarsh, J.M. (2006) Quantification of Plastic Strain of Stainless Steel and Nickel Alloy by Electron Backscatter Diffraction. ActaMeterialia, 54, 539-548.

[8] Yoda, R., Yokomaku, T. and Tsuji, N. (2010) Plastic Deformation and Creep Damage Evaluations of Type 316 Austenitic Stainless Steels by EBSD. Materials Characterization, 61, 913-922.

[9] Githinji, D.N., Northover, S.M., Bouchard, P.J. and Rist, M.A. (2013) An EBSD Study of the Deformation of Service-Aged 316 Austenitic Steel. Metallurgical and Materials Transactions A, 44, 4150-4167. https://doi.org/10.1007/s11661-013-1787-7

[10] Sakakibara, Y., Kubushiro, K., Nomura, K. and Takahashi, S. (2011) EBSD Analysis of Plastic Strain for Austenitic Stainless Steels. Proceedings of ATEM11, OS15F124, Kobe, Japan Society of Mechanical Engineers, 19-21 September 2011, Paper No. OS15-2-3.

[11] Kamaya, M. (2011) Assessment of Local Deformation Using EBSD: Quantification of Accuracy of Measurement and Definition of Local Gradient. Ultramicroscopy, 111, 1189-1199.

[12] Demir, E., Raabe, D., Zaafarami, N. and Zaefferer, S. (2009) Investigation of the Indentation Size Effect through the Measurement of the Geometrically Necessary Dislocation Beneath Small Indents of Different Depths Using EBSD Tomography. 
Acta Materialia, 57, 559-569.

[13] He, W., Ma, W. and Pantleon, W. (2008) Microstructure of Individual Grains in Cold-Rolled Aluminum from Orientation Inhomogeneous Resolved by Electron Backscattering Diffraction. Materials Science and Engineering A, 49, 421-427.

[14] Kubin, L.P. and Mortensen, A. (2003) Geometrically Necessary Dislocation and Strain-Gradient Plasticity: A Few Critical Issues. Scripta Materialia, 48, 119-125.

[15] Gao, H., Huang, Y., Nix, W.D. and Hutchinson, J.W. (1999) Mechanism-Based Strain Gradient Plasticity-I. Theory. Journal of Mechanics and Physics of Solids, 47, 1239-1263.

[16] Ramazani, A., Schwedt, A., Aretz, A., Prahl, U. and Bleck, W. (2013) Characterization and Modelling of Failure Initiation in DP Steel. Computational Materials Science, 75, 35-44.

[17] Sakakibara, Y., Nomura, K., Kubushiro, K. and Yoshizawa, H. (2012) Plastic Strain Dependency of Misorientation for Austenitic Stainless Steel and Nickel Base Alloy. Journal of Japan Institute of Metals and Materials, 76, 669-676.

https://doi.org/10.2320/jinstmet.76.669

Submit or recommend next manuscript to SCIRP and we will provide best service for you:

Accepting pre-submission inquiries through Email, Facebook, LinkedIn, Twitter, etc. A wide selection of journals (inclusive of 9 subjects, more than 200 journals)

Providing 24-hour high-quality service

User-friendly online submission system

Fair and swift peer-review system

Efficient typesetting and proofreading procedure

Display of the result of downloads and visits, as well as the number of cited articles

Maximum dissemination of your research work

Submit your manuscript at: http://papersubmission.scirp.org/

Or contactwjm@scirp.org 